\title{
Sheep and goats in Narok
}

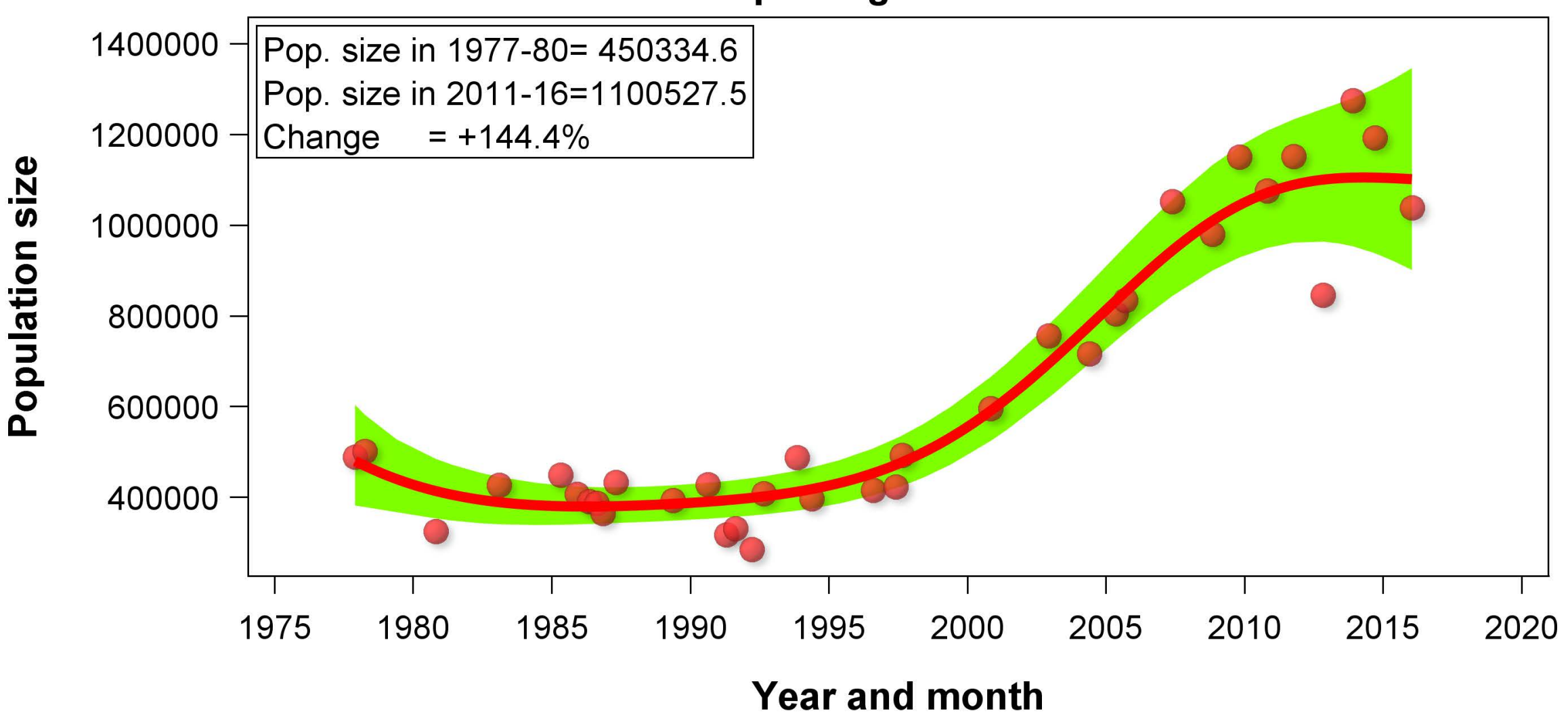




\section{Donkeys in Narok}

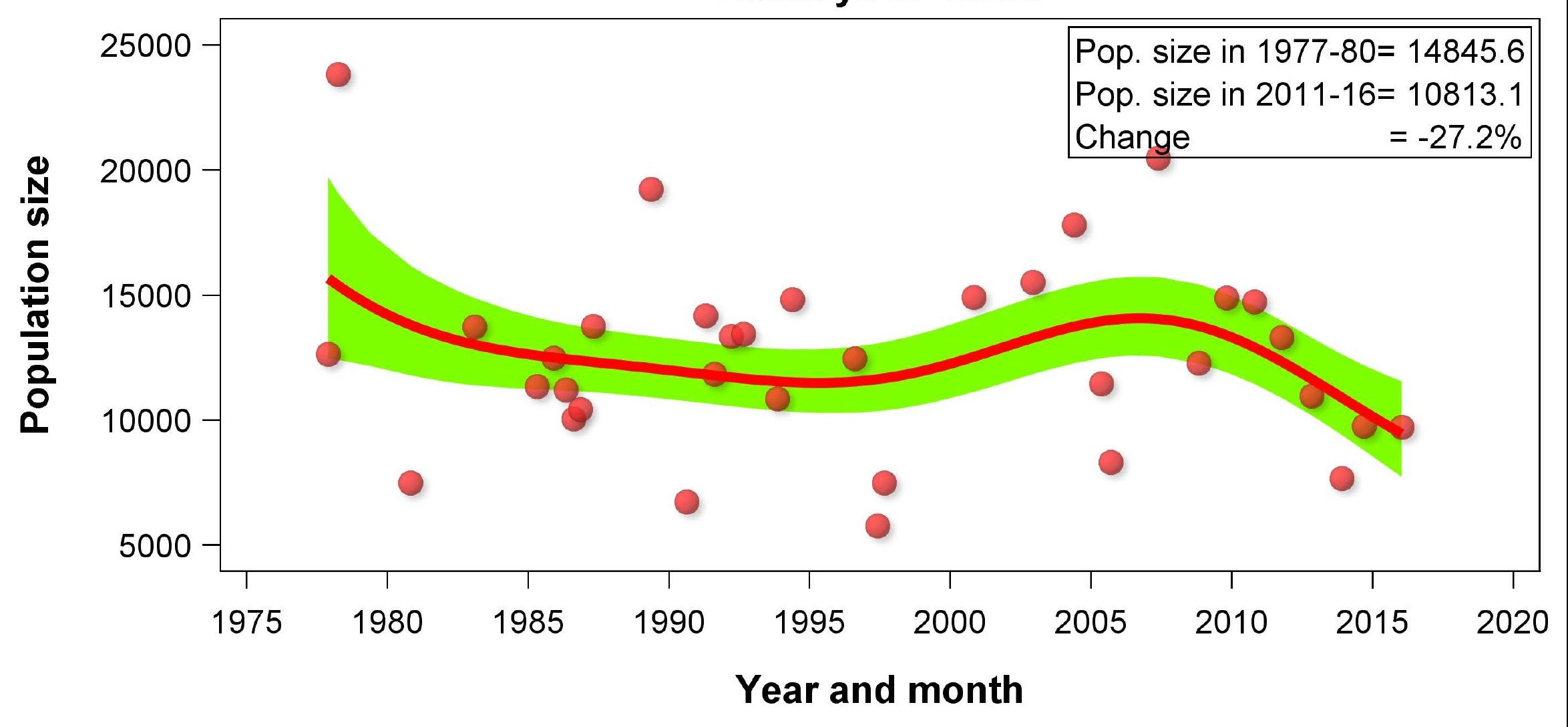




\section{Cattle in Narok}

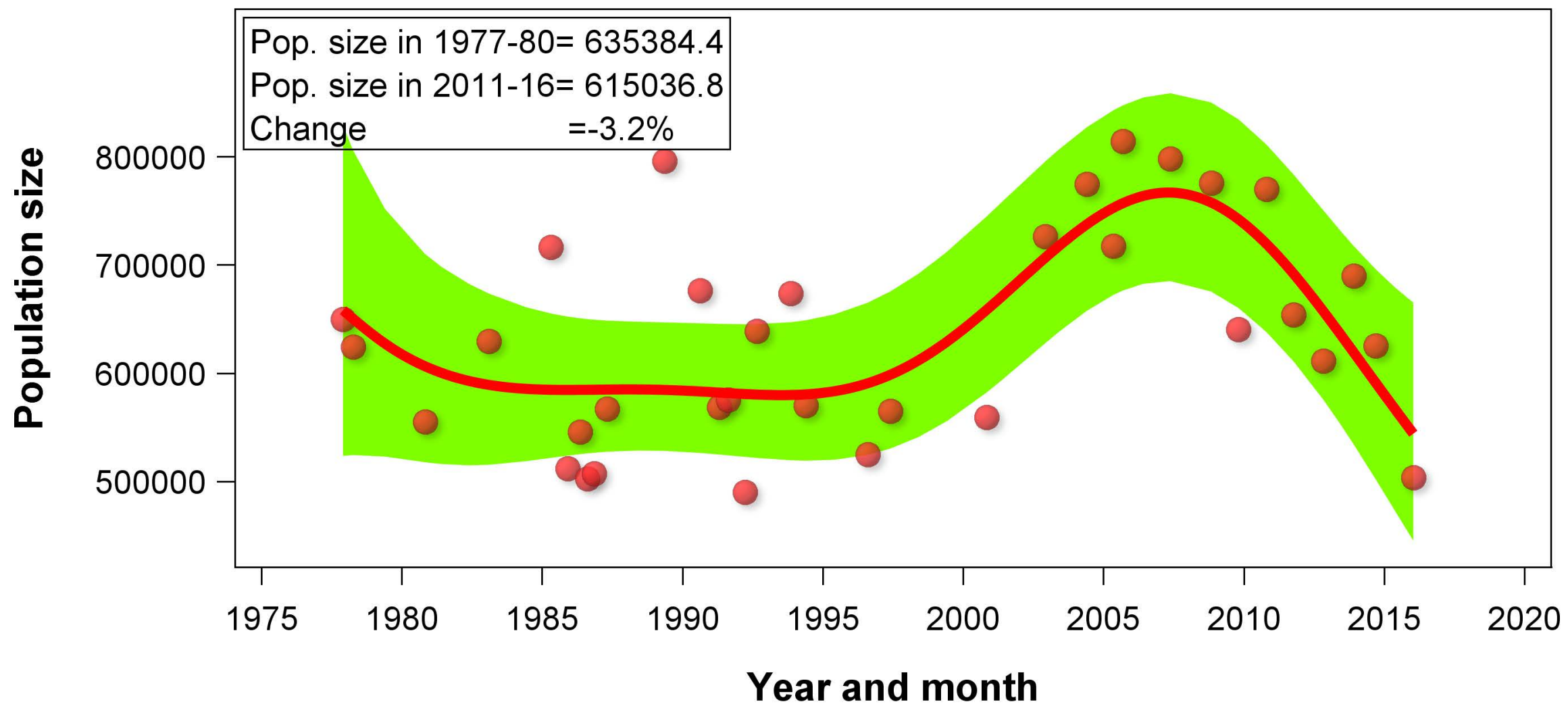


Burchell's zebra in Narok in the dry season

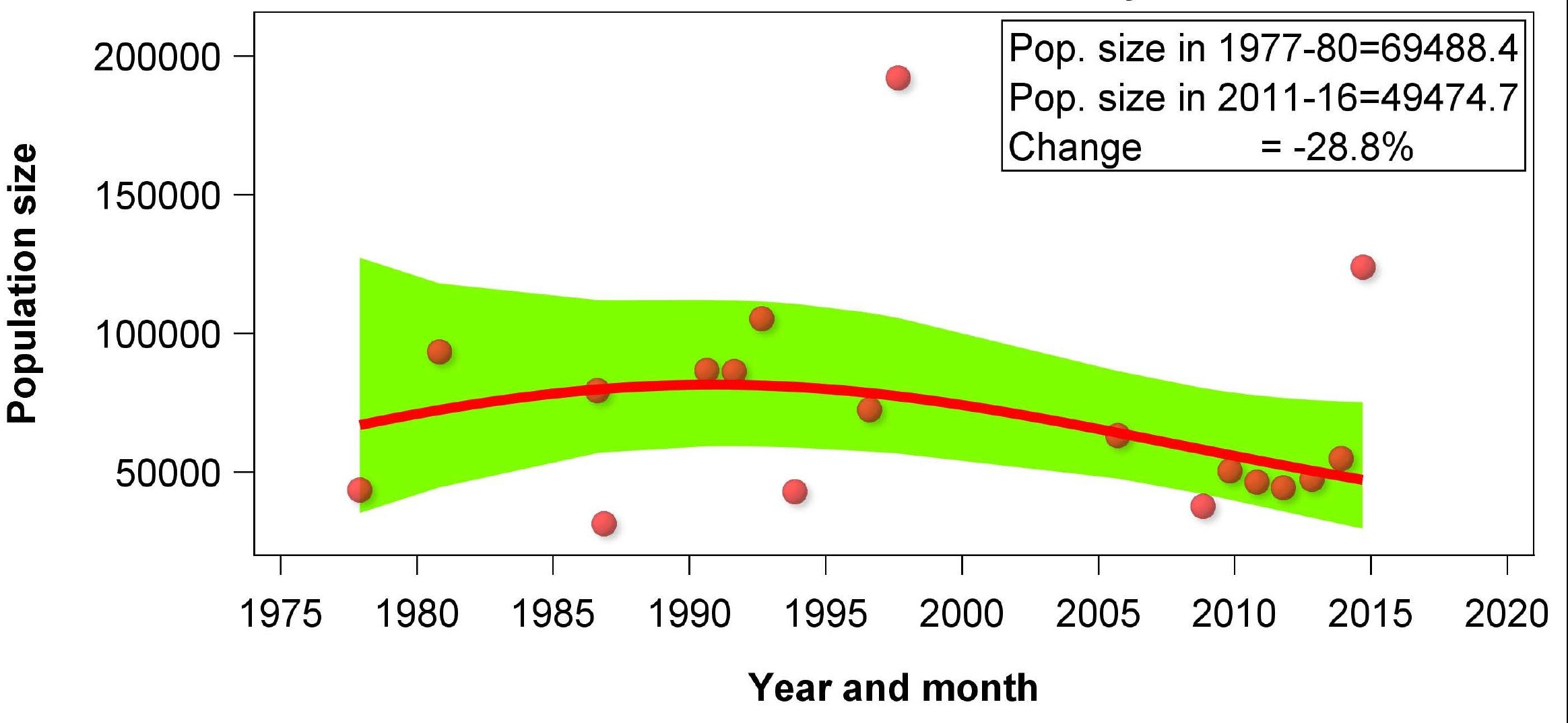




\section{Burchell's zebra in Narok in the wet season}

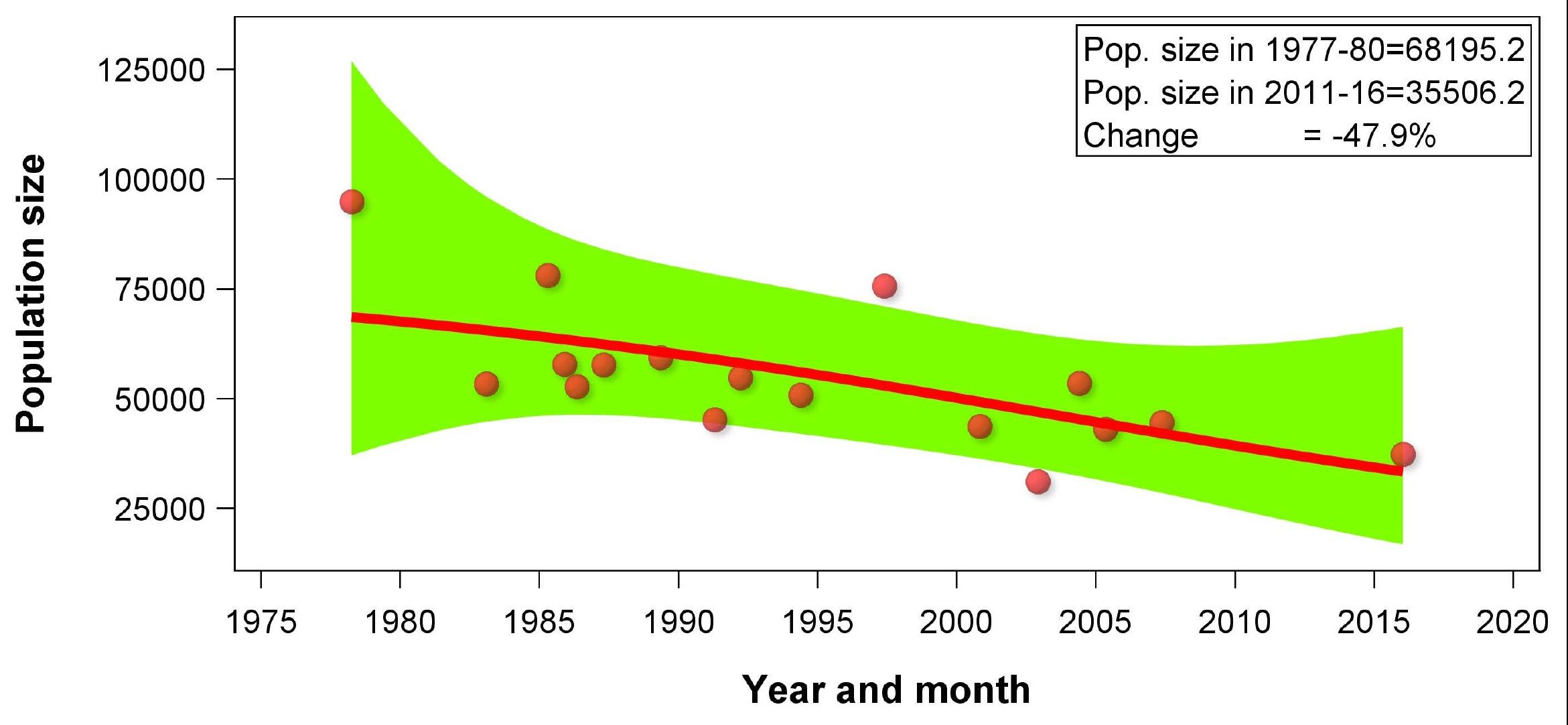




\section{Buffalo in Narok}

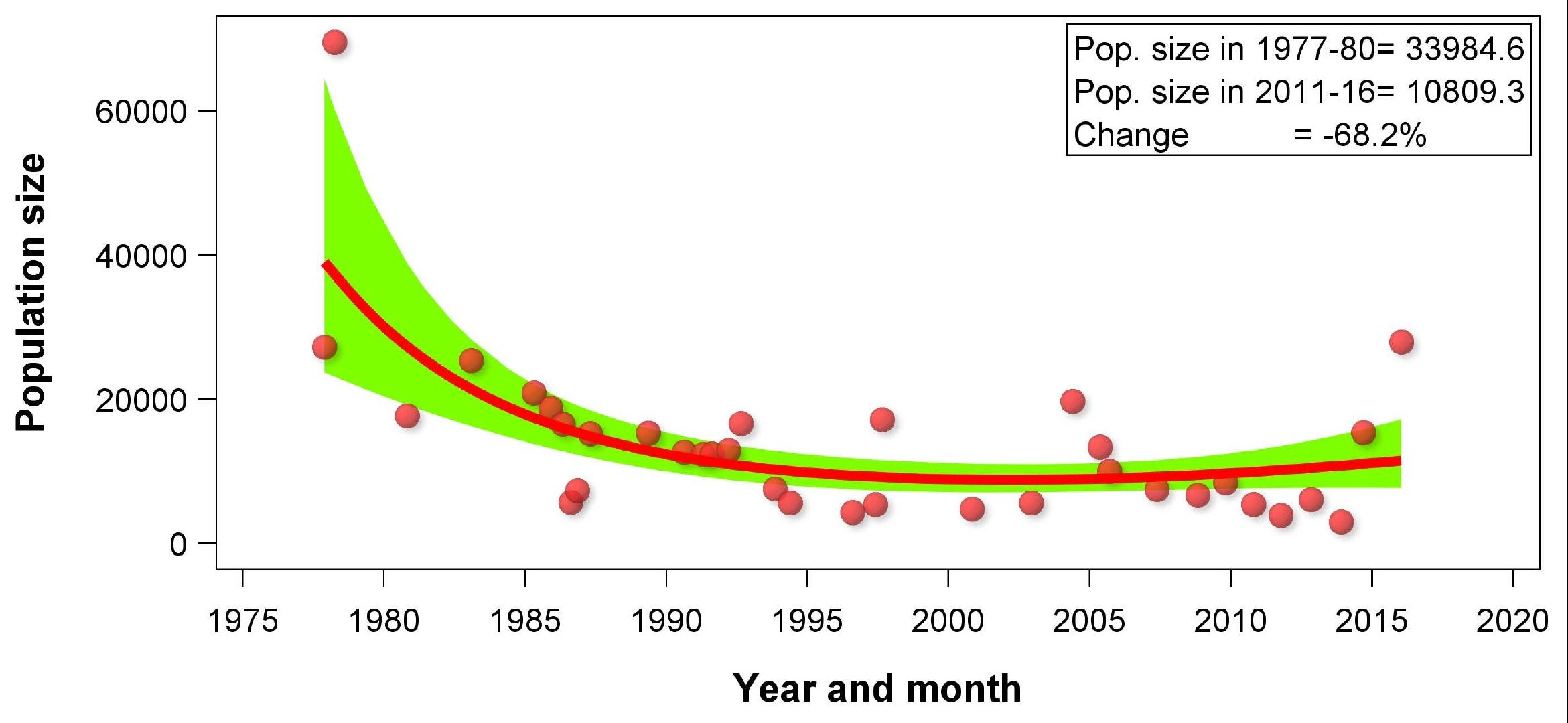




\section{Elephant in Narok}

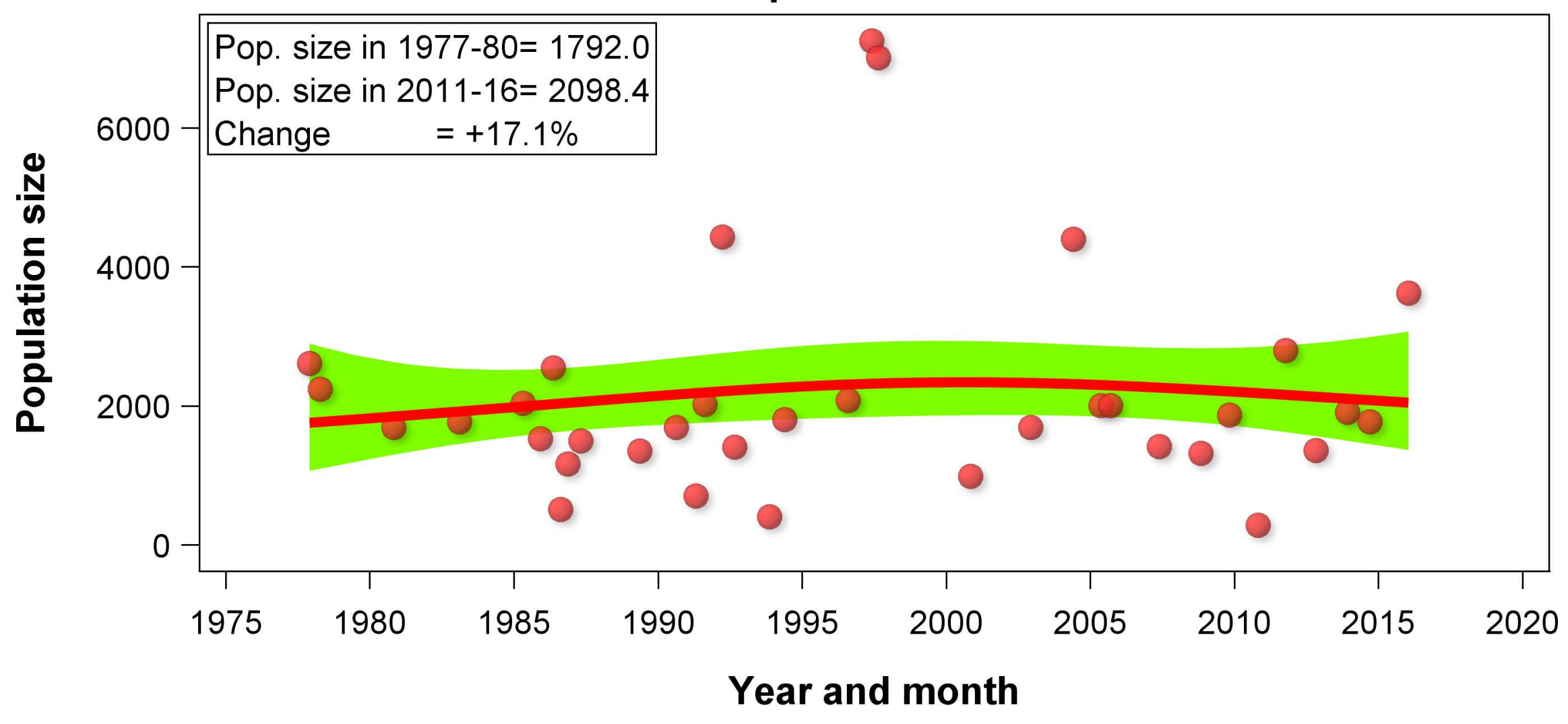




\section{Ostrich in Narok}

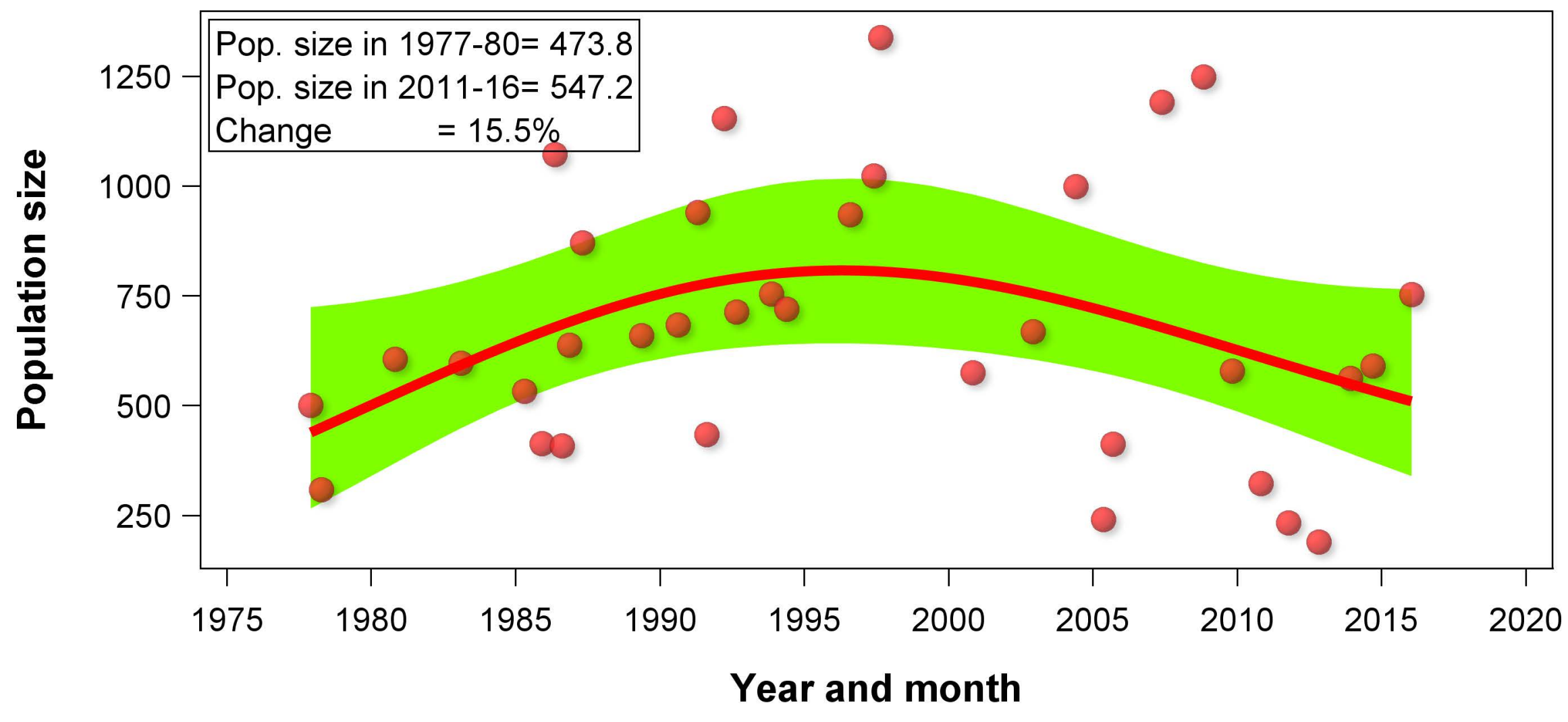




\section{Wildebeest in Narok in the dry season}

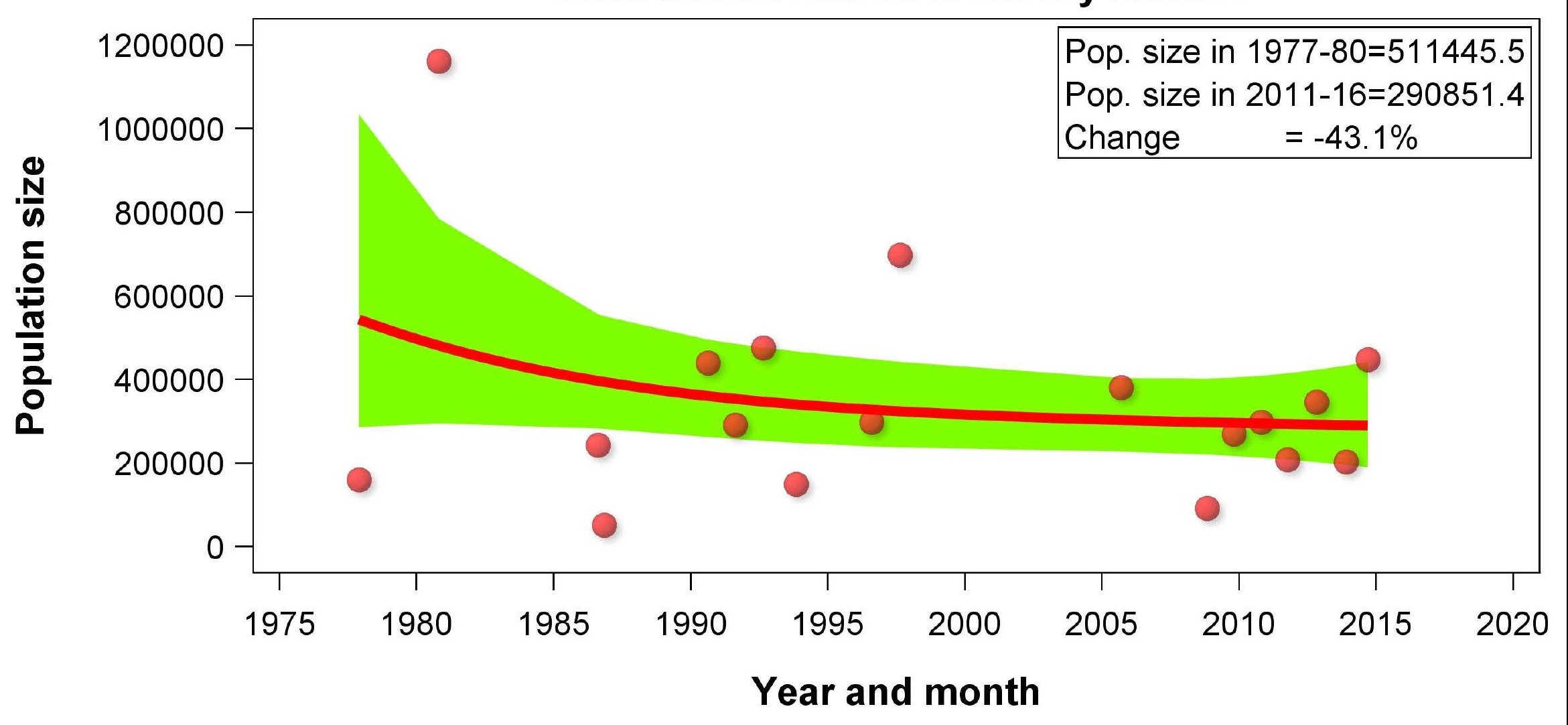




\section{Wildebeest in Narok in the wet season}

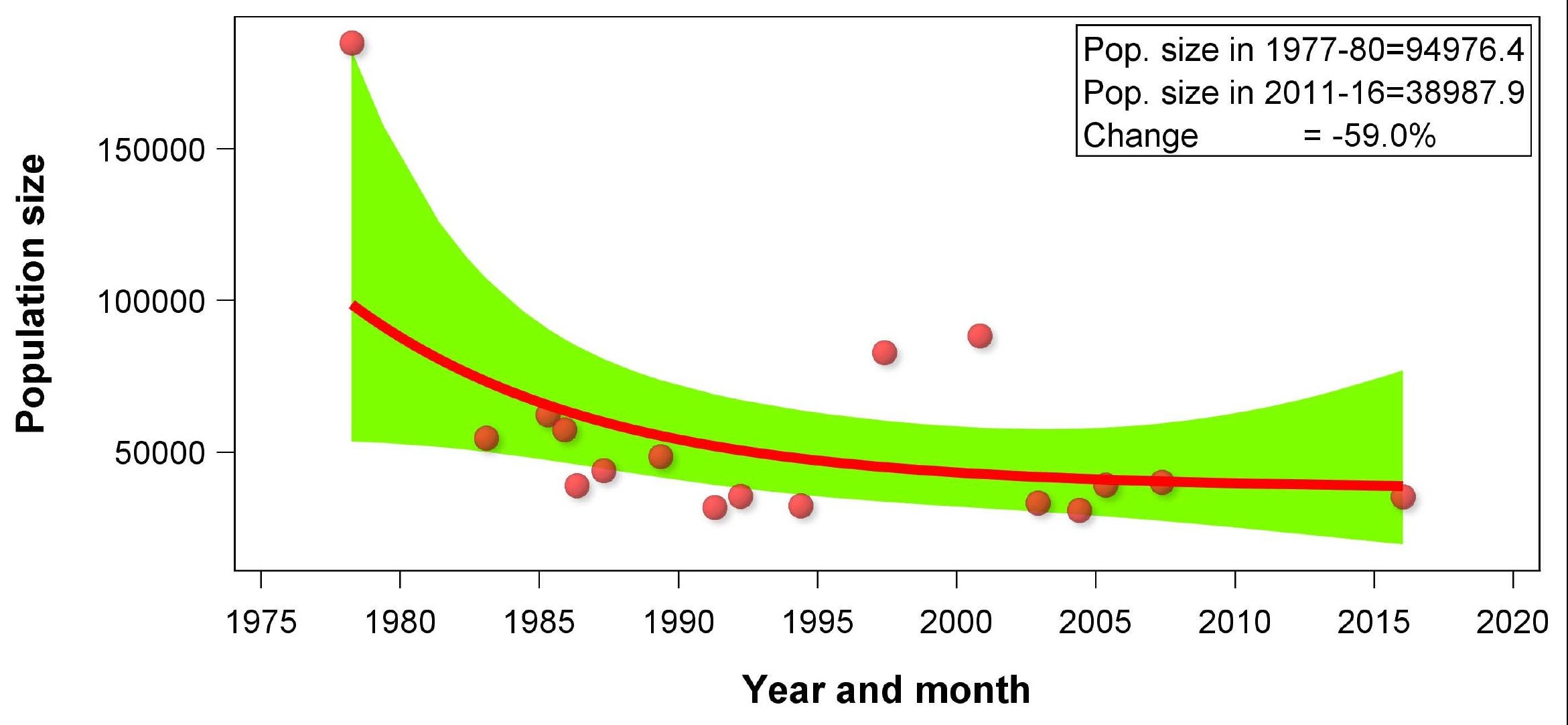




\section{Giraffe in Narok}

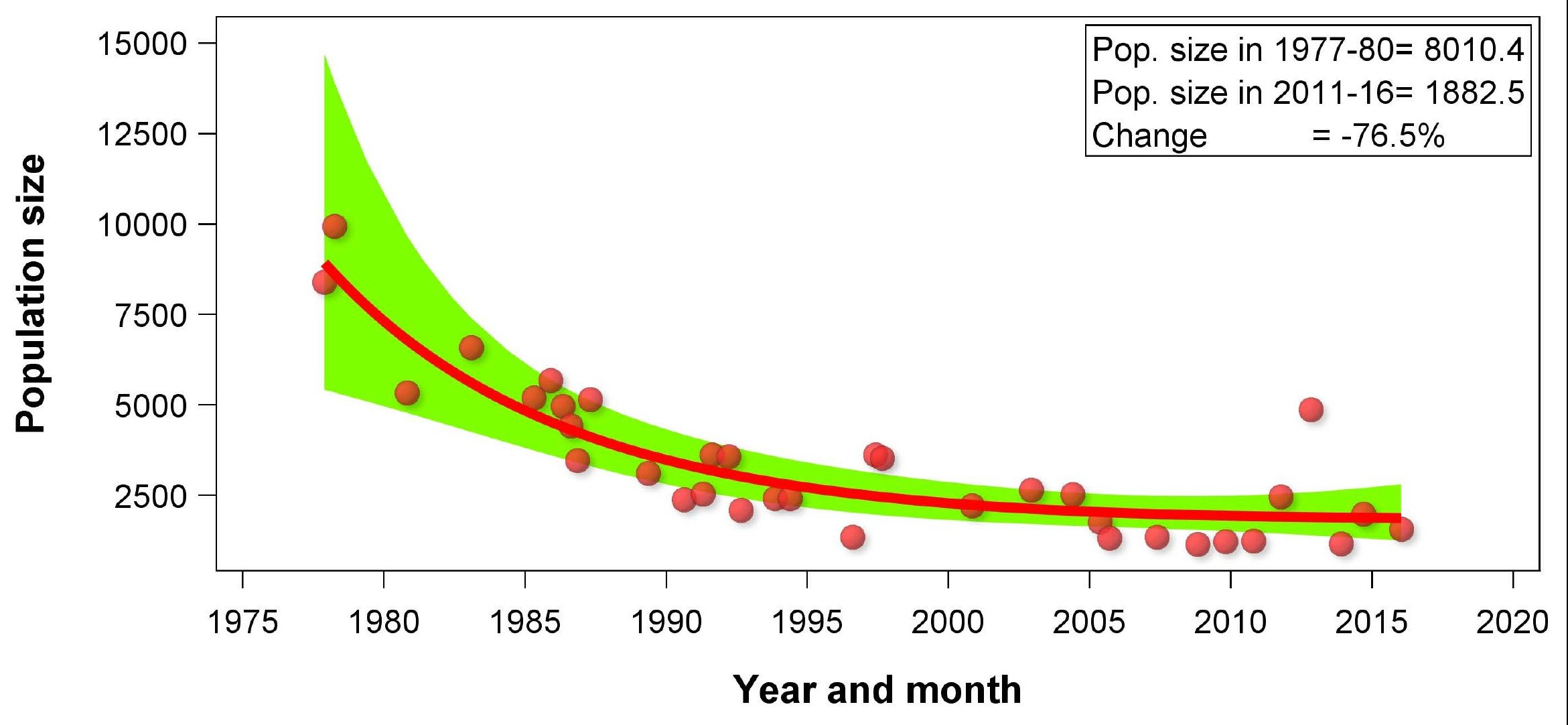




\section{Grant's gazelle in Narok}

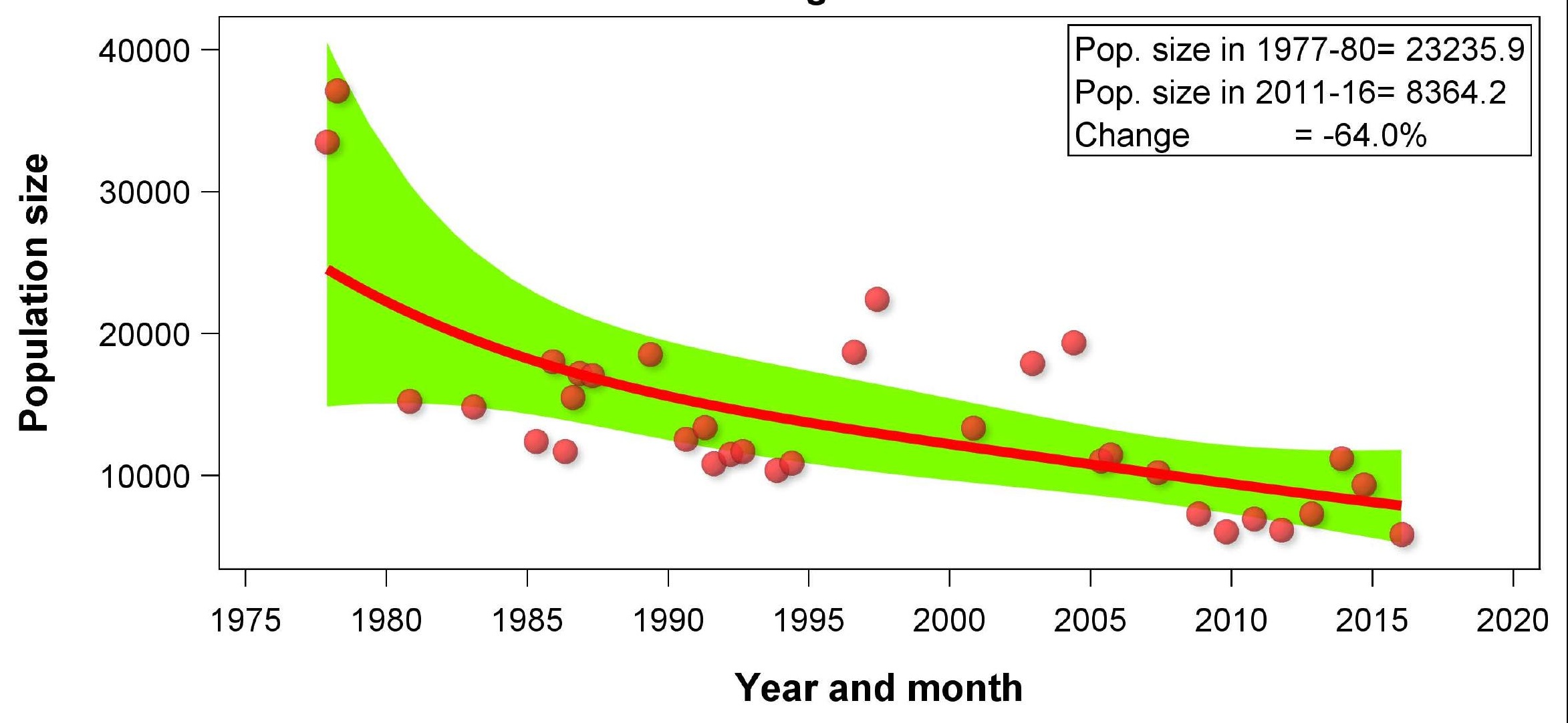




\section{Warthog in Narok}

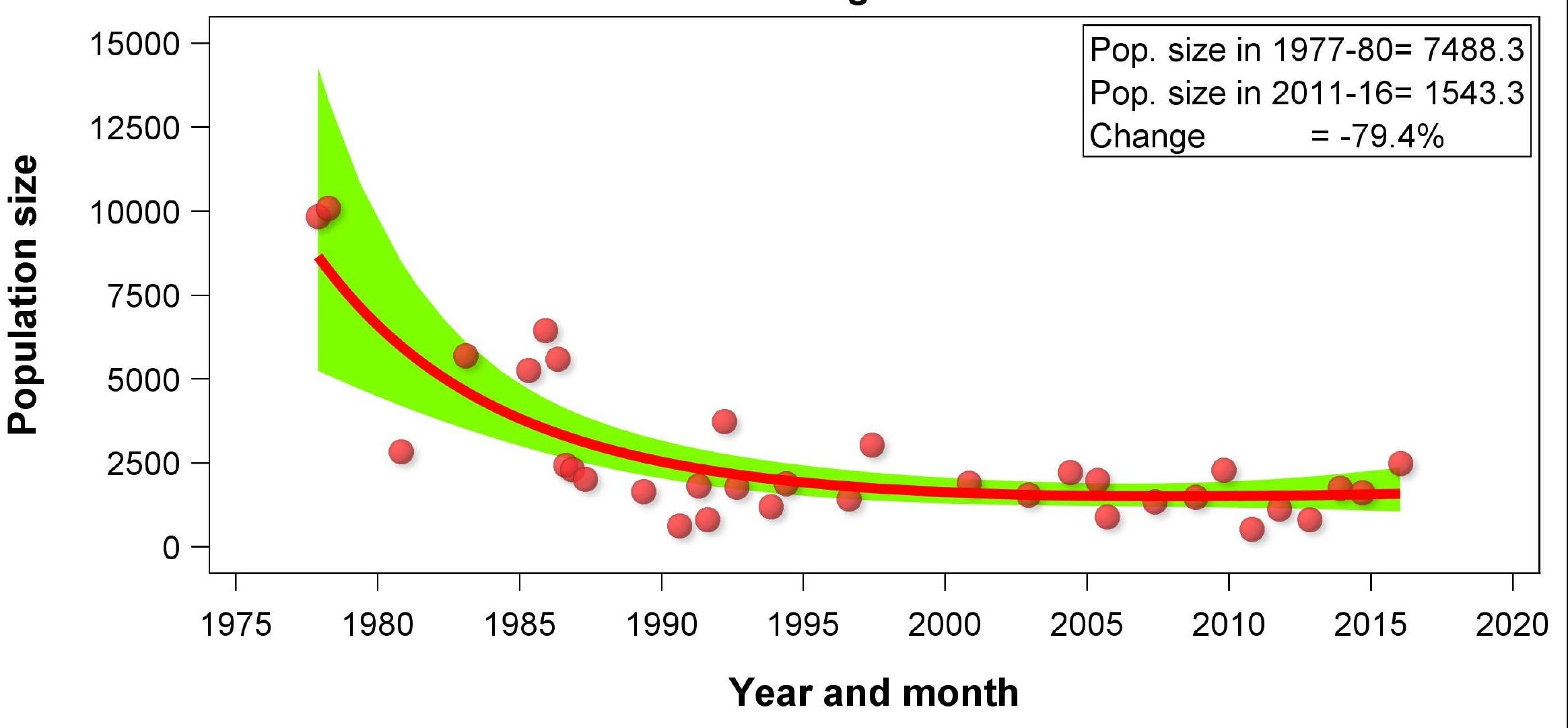




\section{Thomson's gazelle in Narok}

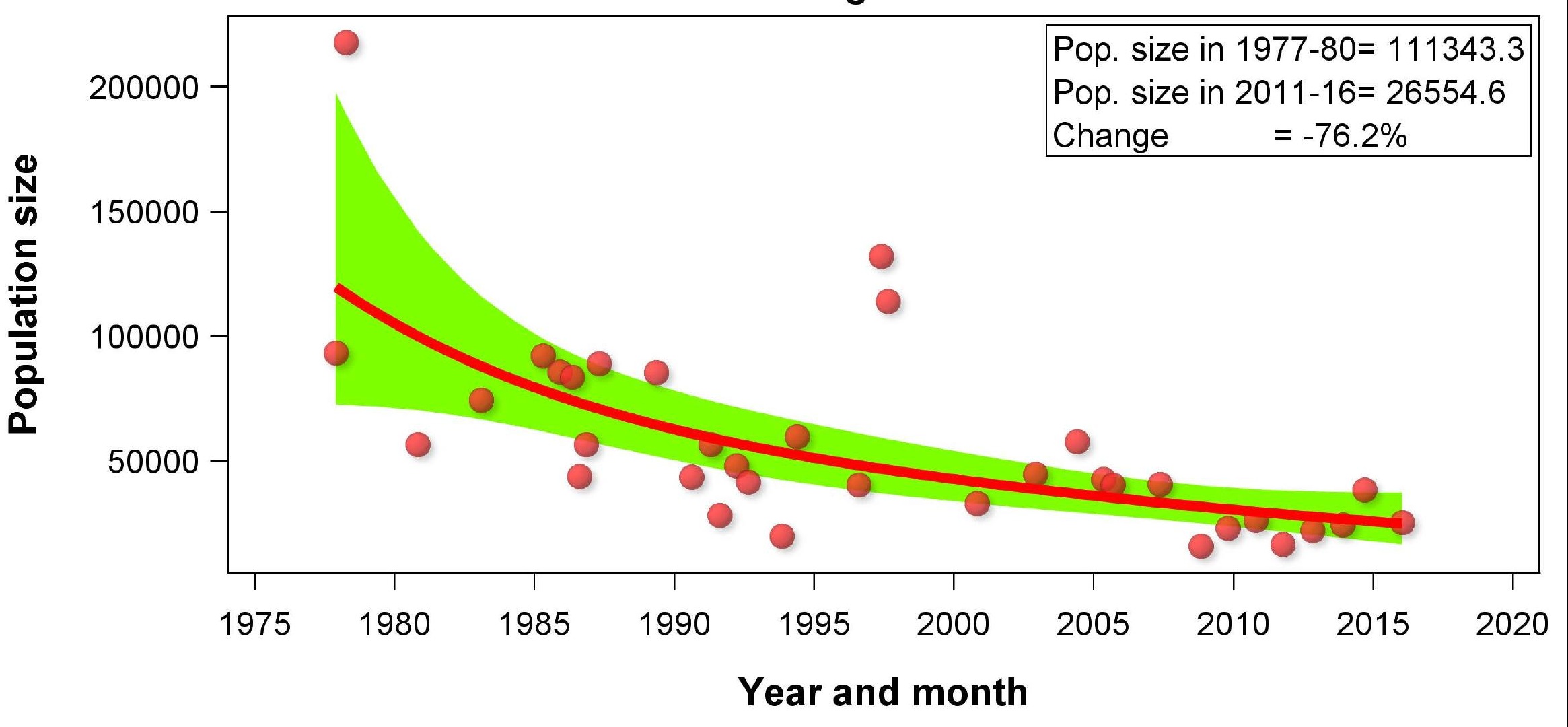




\section{Eland in Narok}

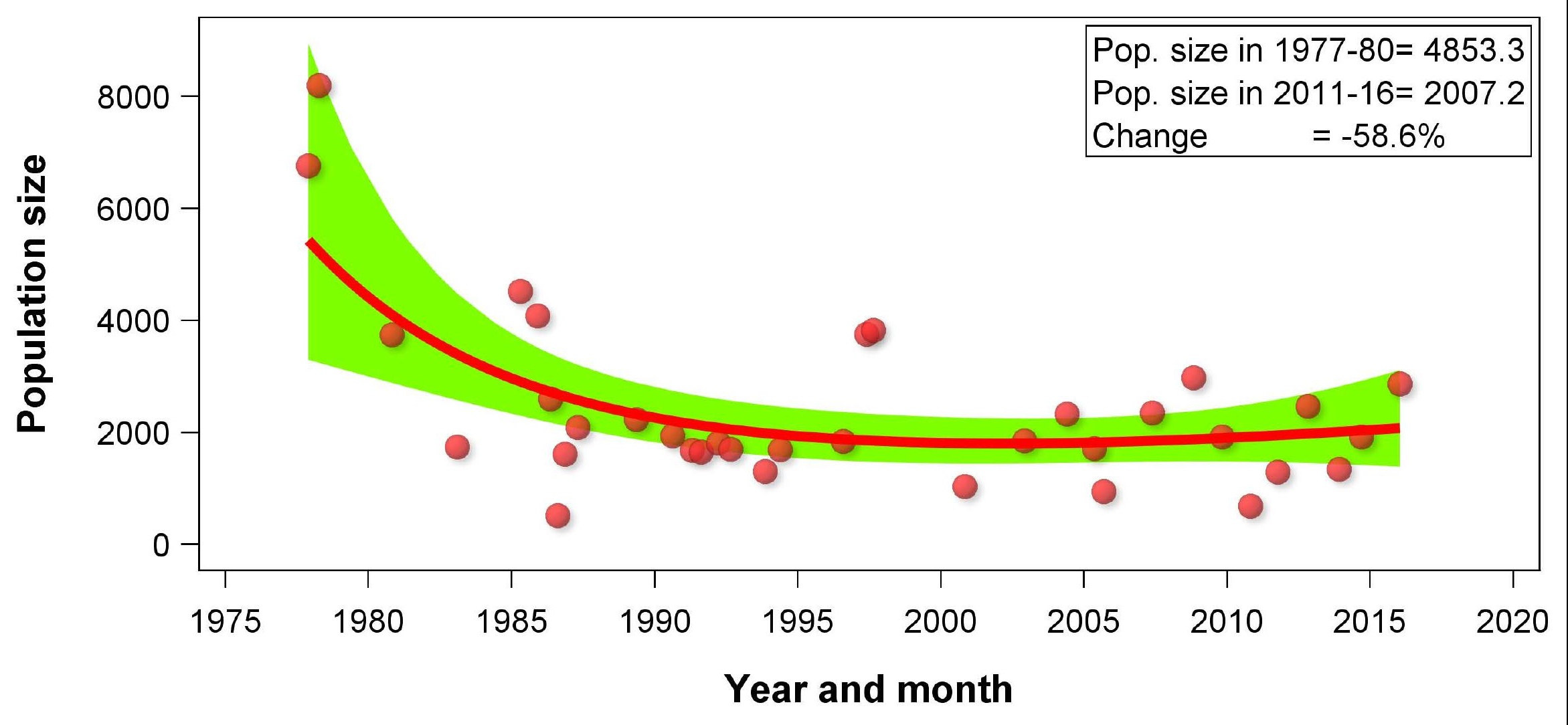




\section{Topi in Narok}

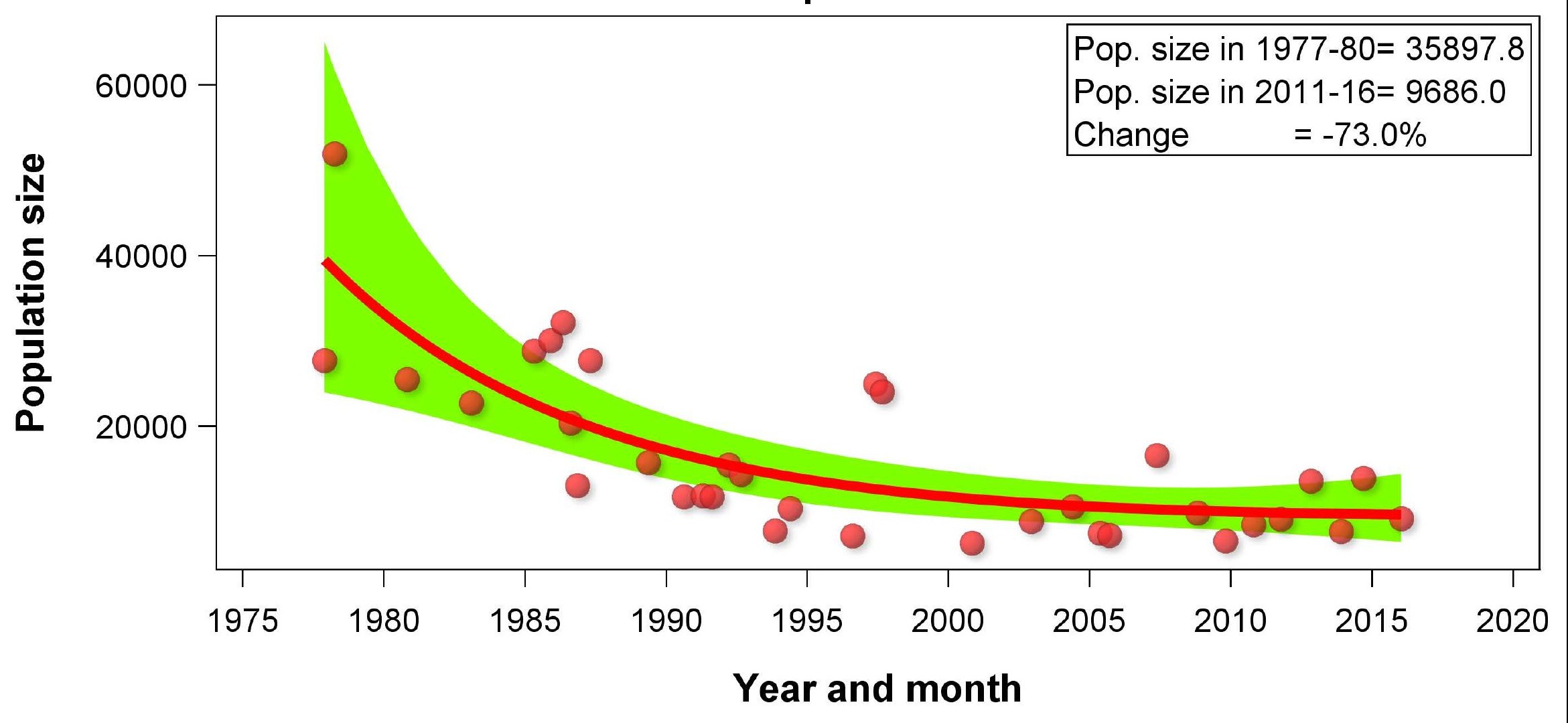




\section{Hartebeest in Narok}

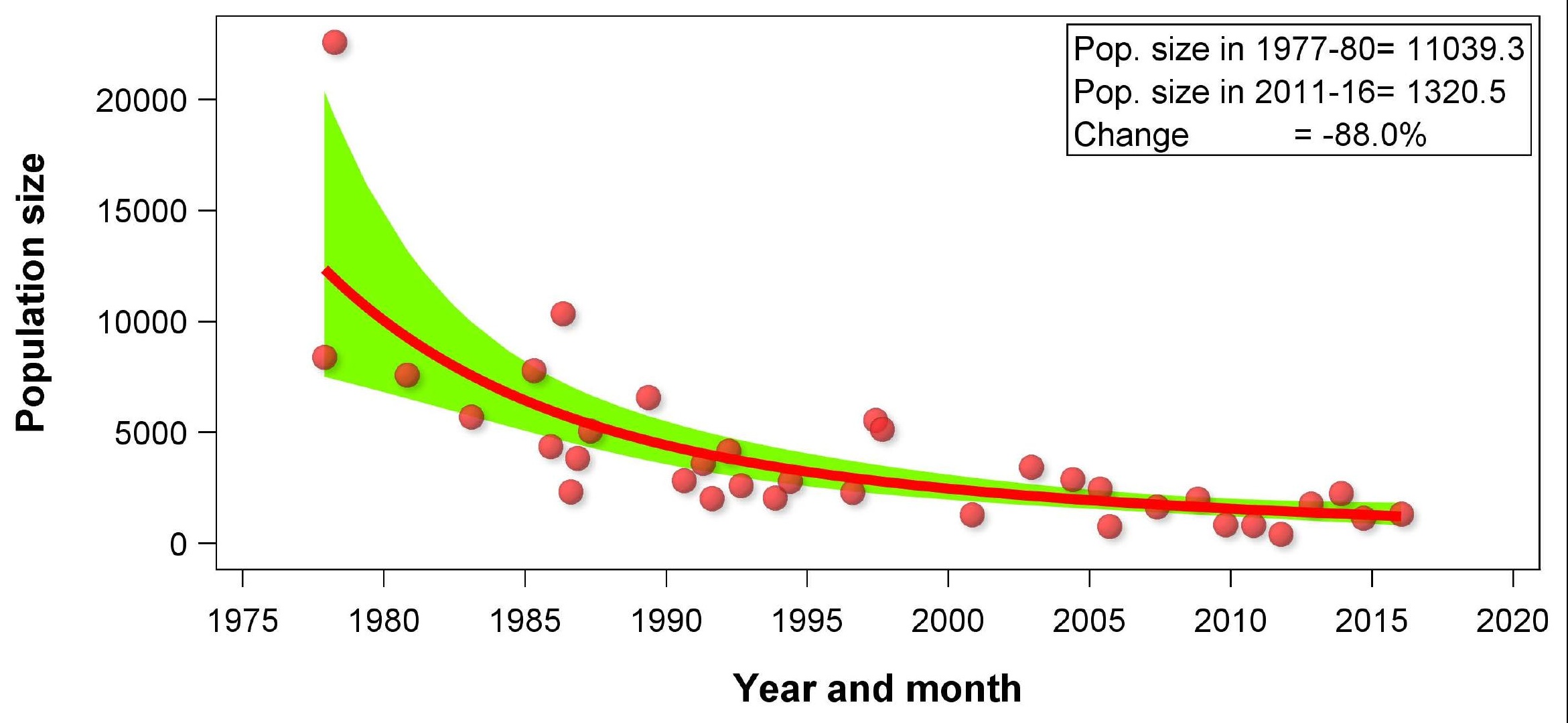




\section{Impala in Narok}

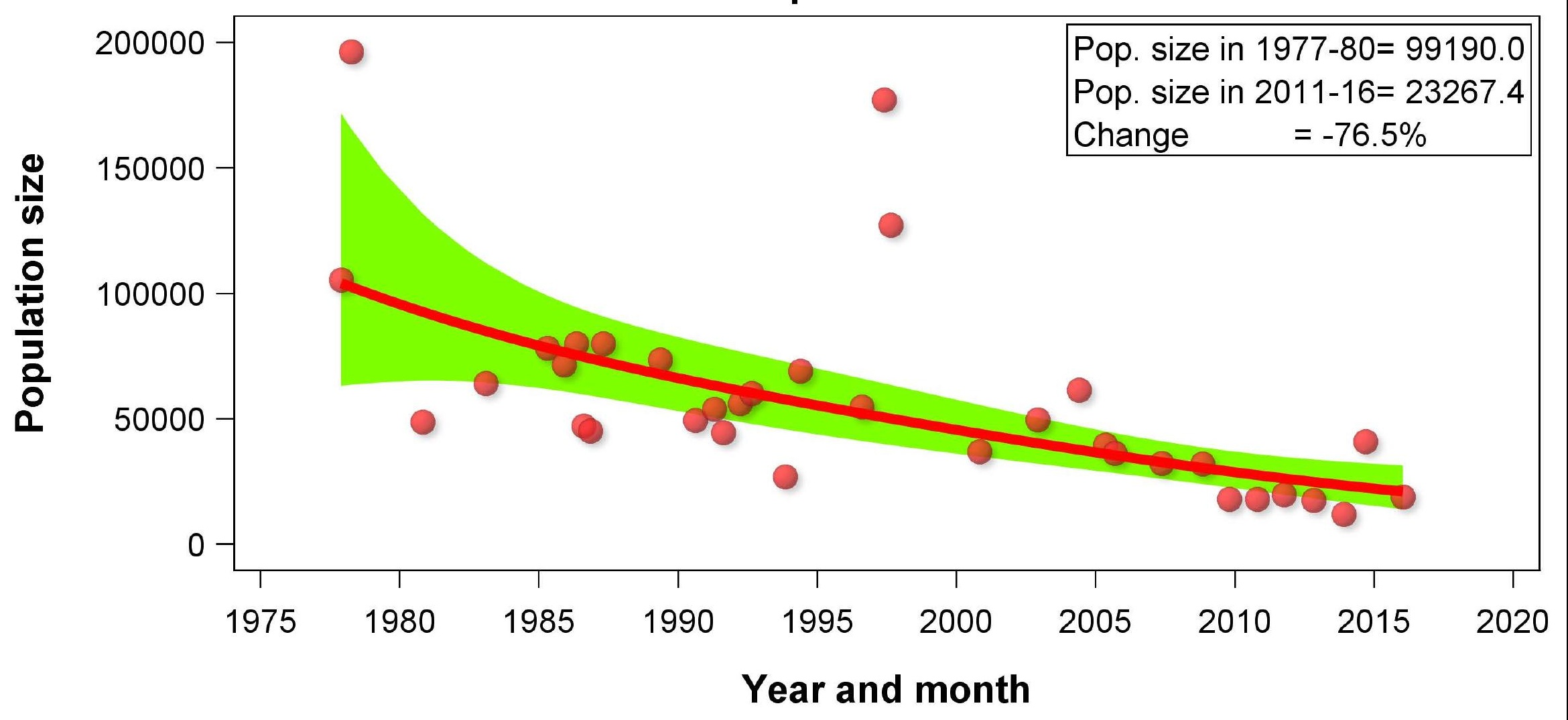




\section{Waterbuck in Narok}

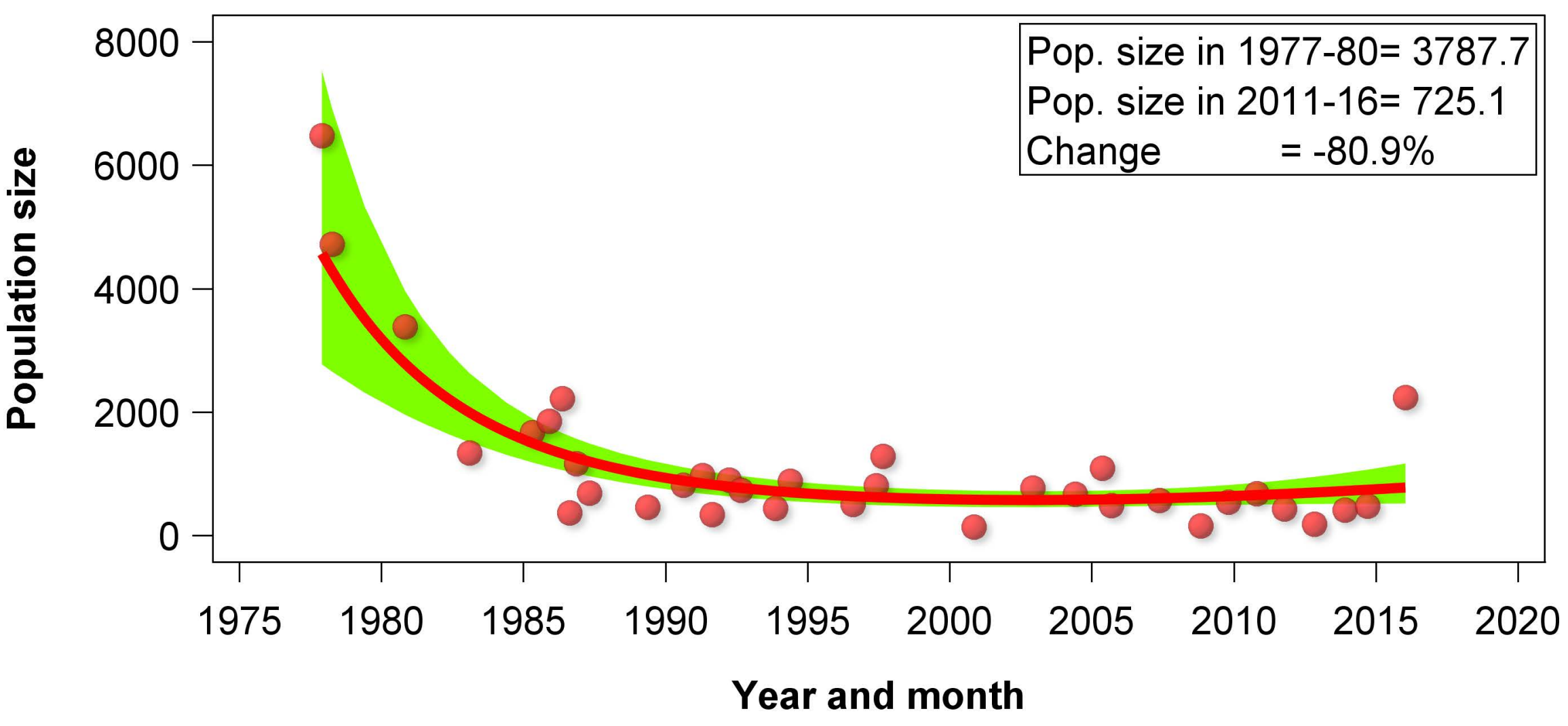

